\title{
Isolation and characterization of autolysis-defective mutants of Escherichia coli that are resistant to the lytic activity of seminalplasmin
}

\author{
Sanjay N. Chitnis, Kolli S. N. Prasad and Pushpa M. Bhargava* \\ Centre for Cellular and Molecular Biology; Hyderabad 500 007, India
}

(Received 8 August 1989; revised 10 November 1989; accepted 21 November 1989)

\begin{abstract}
Two temperature-sensitive autolysis-defective mutants of Escherichia coli were isolated and shown to be resistant to lysis induced by seminalplasmin, an antimicrobial protein from bovine seminal plasma, as well as to lysis induced by ampicillin, D-cycloserine and nocardicin, at 37 or $42{ }^{\circ} \mathrm{C}$ but not at $30^{\circ} \mathrm{C}$. The mutants were, however, sensitive to inhibition of RNA synthesis by seminalplasmin even at the nonpermissive temperature. Temperature-resistant revertants of the mutants were sensitive to lysis induced by the various antibiotics at 37 or $42{ }^{\circ} \mathrm{C}$. The mutations in both strains were mapped at $58 \mathrm{~min}$ on the $E$. coli linkage map. The lysis resistance of the mutants was phenotypically suppressed by the addition of $\mathrm{NaCl}$. Partial suppression of the lysis-resistant phenotype was also observed in a relA genetic background.
\end{abstract}

\section{Introduction}

Seminalplasmin, a $5411 \mathrm{Da}$ basic protein originally isolated as an antibacterial protein from bovine seminal plasma (Reddy \& Bhargava, 1979), is now known to have a wide variety of effects on biological systems (Shivaji \& Bhargava, 1987; Shivaji et al., 1989). We recently found that seminalplasmin lyses bacteria at concentrations higher than those required for bactericidal activity; characterization of the lytic activity of seminalplasmin led us to the hypothesis that the protein lyses bacteria by activating autolysis (Chitnis et al., 1987).

In order to test our hypothesis and to get an insight into the mechanism of lysis of Escherichia coli by seminalplasmin, we have isolated mutants of $E$. coli deficient in autolysis by a procedure similar to that described by Harkness \& Ishiguro (1983). The mutants thus obtained were found to be resistant to seminalplasmin-induced lysis. In this paper we describe our studies on these mutants and compare their properties with those of similar mutants isolated earlier (Harkness \& Ishiguro, 1983; Shimmin et al., 1984) in the context of regulation of autolysis in E. coli.

\section{Methods}

Bacterial and phage strains. The bacterial strains used in this study were all derivatives of $E$. coli K12. They are described in Table 1. Phage

Abbreviations: TSB, tryptic soy broth; MTC, maximum tolerable concentration.
P1-kc, used for transduction, and phage $\lambda \mathrm{NK} 370$, used in the Tn10 transposition experiments, were from our laboratory stocks.

Media. Media used in this study included minimal A, LB (Miller, 1972) and tryptic soy broth (TSB; Hi Media Laboratories, Bombay, India). Media were solidified by the addition of agar (Difco) to a final concentration of $1.5 \%(\mathrm{w} / \mathrm{v})$. When used, the concentration of tetracycline was $5 \mu \mathrm{g} \mathrm{ml}^{-1}$ in minimal medium and $15 \mu \mathrm{g} \mathrm{ml}^{-1}$ in enriched medium.

Chemicals. L-Amino acids and D-cycloserine were purchased from Sigma. Nocardicin was a gift from K. Murayama of Fujisawa Pharmaceutical Co. Ltd, Japan. Ampicillin and tetracycline were purchased from local pharmaceutical sources. $\left[{ }^{3} \mathrm{H}\right]$ Uridine was obtained from Bhabha Atomic Research Centre, Bombay, India. All other chemicals used were of analytical grade.

Seminalplasmin. Seminalplasmin was purified from bovine seminal plasma as described earlier (Reddy \& Bhargava, 1979); the CMSephadex-purified fraction was used in the studies described here.

Isolation of mutants. Temperature-sensitive autolysis-defective mutants were isolated by a procedure similar to that described by Harkness \& Ishiguro (1983). Strain C90 was mutagenized with ethyl methanesulphonate (Miller, 1972) and the survivors were grown in TSB overnight at $30^{\circ} \mathrm{C}$. The population of mutagenized cells was subcultured and grown at $30^{\circ} \mathrm{C}$ to a density of about $1 \times 10^{8}$ cells ml $^{-1}$. The culture was shifted to $42^{\circ} \mathrm{C}$ for 30 min before D-cycloserine was added to a final concentration of $50 \mu \mathrm{g} \mathrm{ml}^{-1}$. Incubation at $42^{\circ} \mathrm{C}$ was continued until no further decrease in $\mathrm{OD}_{600}$ could be seen. The surviving cells were collected by centrifugation, washed once with minimal A containing $0.9 \% \mathrm{NaCl}$, and grown overnight at $30^{\circ} \mathrm{C}$. The procedure described above was repeated the next day, with the modification that ampicillin at $1 \mathrm{mg} \mathrm{ml}^{-1}$ was used instead of $\mathrm{D}$ cycloserine for inducing lysis at $42^{\circ} \mathrm{C}$, and yet again on the third day, with D-cycloserine.

The survivors of the final D-cycloserine treatment were grown overnight at $30^{\circ} \mathrm{C}$ and plated on TSB plates at $30^{\circ} \mathrm{C}$. Individual colonies were then tested for temperature sensitivity (lack of colony 
Table 1. Bacterial strains

\begin{tabular}{|c|c|c|}
\hline Strain & Relevant characteristics & Source or reference \\
\hline $\mathrm{C} 90$ & HfrC phoss & Bachmann (1972) \\
\hline CSH57 & $\mathrm{F}^{-}$purE trp his arg met ilv leu thi ara lac $Y$ gal malA $x y l$ mtl rpsL & Miller (1972) \\
\hline KL16 & Hfr (PO45) thi-1 relal spoTI & Low (1972) \\
\hline GJ157 & 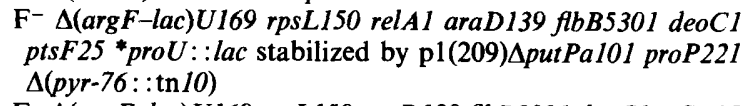 & Gowrishankar (1985) \\
\hline GJ216 & $\begin{array}{c}\mathrm{F}^{-} \Delta(\text { argF-lac }) U 169 \text { rpsL150 araD139 fbB5301 deoC1 ptSF25 } \\
\Delta \text { putPA101 proP222 } \Delta(\text { pyr76::Tn10) recA srl::Tn10 }\end{array}$ & Gowrishankar (1985) \\
\hline GJ46 & $\begin{array}{l}\mathrm{F}^{-} \Delta(\arg F-l a c) U 169 \text { rpsL150 relAl araD139 fibB5301 deoCl } \\
\text { ptsF } 25 \text { zfi-900::Tn10 }\end{array}$ & Gowrishankar (1985) \\
\hline NF161 & metBl $\arg A 52$ spoTl & \\
\hline NF162 & metBI arg A52 spoTI relA1 & \\
\hline CCMB1001 & C90 lyt-1(ts) & This study \\
\hline CCMB1002 & C90 lyt-2(ts) & This study \\
\hline CCMB 1003 & Temperature-resistant revertant of CCMB1001 & This study \\
\hline CCMB1004 & C90 zfi-905: :Tn 10 & This study \\
\hline CCMB1005 & CCMB1001 zfi-905::Tn10 & This study \\
\hline ССМB1007 & NF161 lyt-1(ts) zfi-905::Tn 10 & This study \\
\hline CCMB1008 & NF162 lyt-l(ts) zfi-905: :Tn 10 & This study \\
\hline
\end{tabular}

* proU is the new name for the osrA locus defined by Gowrishanker (1985).

formation at $42^{\circ} \mathrm{C}$ ); some of the temperature-sensitive colonies were further purified and screened for resistance to ampicillin- and Dcycloserine-induced lysis.

Genetic techniques. Conjugation was done as described by Miller (1972). Preparation of Plkc lysates and Plkc transduction were performed as described by Gowrishankar (1985). Random transpositions of the tetracycline-resistance transposon, $\operatorname{Tn} 10$, were obtained in C90 with the use of the $\lambda \mathrm{NK} 370$ lysate, essentially by the method of Kleckner et al. (1978).

Antibiotic-induced lysis. Bacterial cultures were initially grown at $30{ }^{\circ} \mathrm{C}$ in a gyratory shaking water bath to an $O D_{600}$ of $0 \cdot 10-0.25$ and then shifted to a shaking water-bath at the desired temperature. After $30 \mathrm{~min}$, the antibiotic was added to the required concentration and lysis was followed by continuously recording the decrease in $\mathrm{OD}_{600}$ of the culture incubated in a cuvette maintained at the desired temperature.

Maximum tolerable concentration (MTC). Bacterial cultures were grown at $30^{\circ} \mathrm{C}$ in a gyratory shaking water-bath to an $\mathrm{OD}_{600}$ of $0 \cdot 1-0 \cdot 2$ and then shifted to a shaking water bath at $42^{\circ} \mathrm{C}$. After $30 \mathrm{~min}$, the antibiotic was added to the desired concentration, incubation continued at $42{ }^{\circ} \mathrm{C}$ and lysis followed by measuring the decrease in $\mathrm{OD}_{600}$ at various time intervals. MTC is defined as the highest concentration of the antibiotic not causing lysis within $2 \mathrm{~h}$.

$R N A$ synthesis. Exponentially growing $E$. coli cells $\left(\mathrm{OD}_{600} 0 \cdot 3\right)$ were incubated with $\left[{ }^{3} \mathrm{H}\right]$ uridine (sp. act. $14 \mathrm{Ci} \mathrm{mmol}^{-1}, 518 \mathrm{GBq} \mathrm{mmol}^{-1}$ ) at a final concentration of $20 \mu \mathrm{Ci} \mathrm{ml}^{-1}$ in TSB. Samples $(0.1 \mathrm{ml})$ taken at various times were treated with $1 \mathrm{ml}$ cold $10 \%(\mathrm{w} / \mathrm{v})$ trichloroacetic acid (TCA) followed by $0.5 \mathrm{mg}$ bovine serum albumin. Precipitation was allowed to continued for $30 \mathrm{~min}$ and the TCA-insoluble material was collected on Whatman GF/C filter paper discs, washed with cold $5 \%$ $(w / v)$ TCA, dried and counted in a toluene-based scintillation fluid.

\section{Results}

\section{Isolation of mutants}

A mutagenized $E$. coli culture was subjected to a threestep enrichment procedure to select for temperature- sensitive, lysis-resistant mutants as described in Methods. The mutant culture thus obtained was plated to obtain single colonies, and the individual colonies were tested for temperature sensitivity. Initially, both temperature-resistant and temperature-sensitive colonies were tested for resistance to lysis by ampicillin. Whereas all the 20 temperature-sensitive colonies tested were resistant to lysis by ampicillin, none of the 20 temperature-resistant colonies tested were observed to be so. Two independent isolations were carried out and two mutants (one from each isolation), designated CCMB1001 and CCMB1002, were chosen for further study. The mutant loci in these two strains are tentatively designated as $l y t-1$ and $l y t-2$ respectively.

\section{Mapping of lyt-1 and lyt-2}

A Tn 10 insertion cotransducible with $l y t-l$ was obtainable as described below. Random transpositions of $\operatorname{Tn} 10$ were obtained in $E$. coli $\mathrm{C} 90$ using the phage vector $\lambda N K 370$, as described by Kleckner et al. (1980). A Plkc lysate grown on a population of the $\mathrm{Tet}^{\mathrm{r}}$ cells was used to transduce the mutant CCMB1001. One of the Tetr, temperature-resistant transductants so obtained (CCMB1004) was shown to have a Tn10 insertion with $85 \%$ linkage to the wild-type allele corresponding to the lyt-1 locus.

Preliminary conjugation experiments between CCMB1004 (itself an $\mathrm{HfrC}$ derivative) and $\mathrm{CSH} 57$ indicated that the site of $\operatorname{Tn} 10$ insertion was between his and $\arg G$. More precise mapping was done (i) by interruption mating after transfer of the $\mathrm{Tn} 10$ insertion into the $\mathrm{Hfr}$ strain $\mathrm{KL16}$, and (ii) by two-factor 


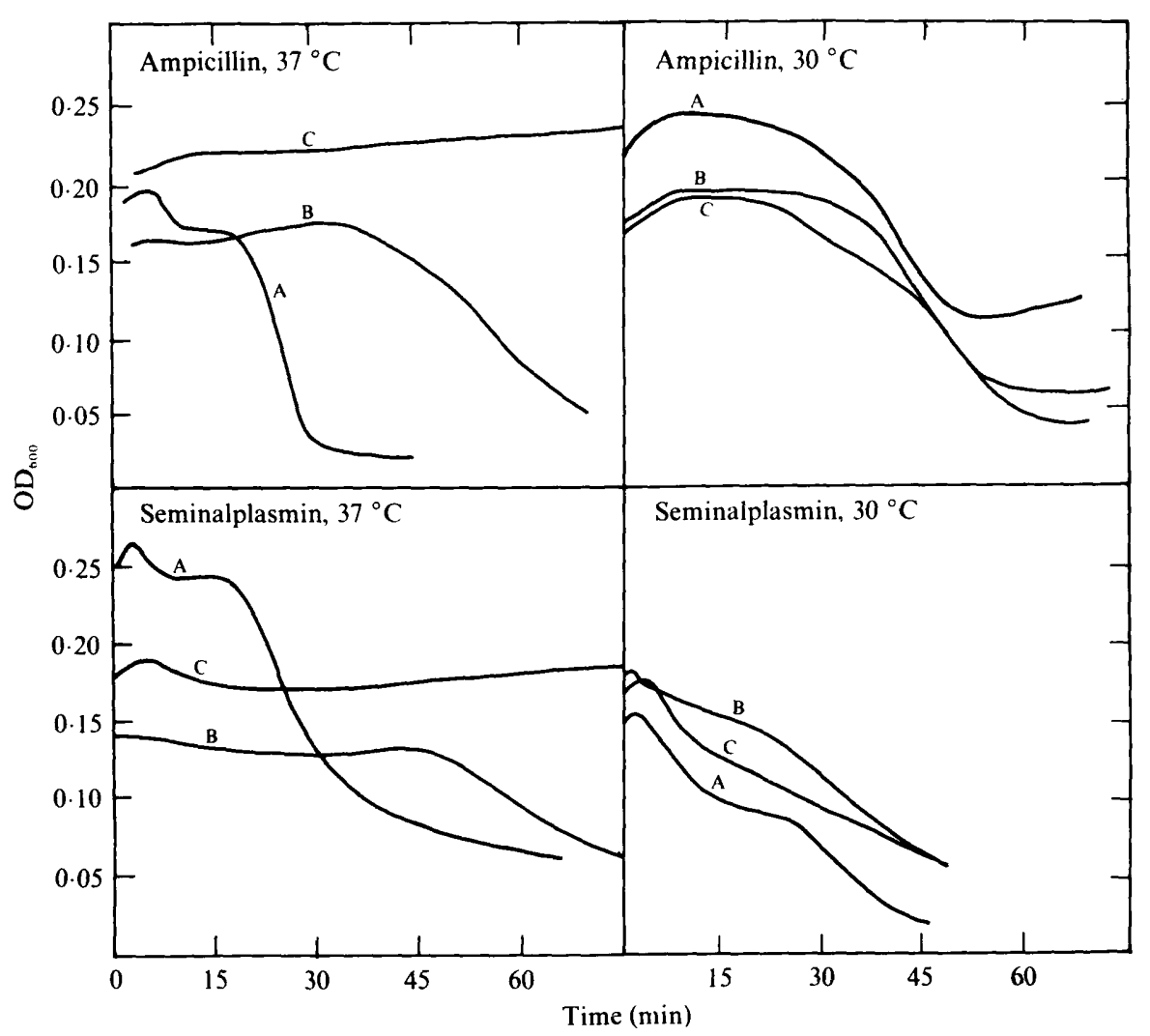

Fig. 1. Lysis of the mutants and wild-type induced by ampicillin $\left(1000 \mu \mathrm{g} \mathrm{ml}^{-1}\right)$ or seminalplasmin $\left(200 \mu \mathrm{g} \mathrm{ml}^{-1}\right)$. Strains $\mathrm{C} 90$ (wildtype) (A), CCMB1001 $\left(l y t-1\right.$, ts) (B) and CCMB1002 (lyt-2, ts) (C) were grown to the exponential phase in TSB at $30^{\circ} \mathrm{C}$ and lysis was studied at the indicated temperature by continuously recording the decrease in $\mathrm{OD}_{600}$ as described in Methods.

transductional linkage analysis with the loci $s r l$ and proU at 58 min on the E. coli map (Bachmann, 1972; Gowrishanker, 1985). In a cross between CCMB1004 (donor, zfi::Tn10) and GJ157 (recipient, proU::lac), 200 out of the $350 \mathrm{Tet}^{\mathrm{r}}$ transductants were lac, indicating that the Tn 10 insertion in CCMB1004 is $57 \%$ cotransducible with proU. In two crosses with CCMB1001 (lyt-1, ts) as recipient and GJ46 (zfi-900::Tn10) or GJ216 $(s r l:: \operatorname{Tn} 10)$ as donor, 55 out of the $90 \mathrm{Tet}^{\mathrm{r}}$ transductants $(61 \%)$ were temperature resistant in the first case and 40 out of the $75 \mathrm{Tet}^{\mathrm{r}}$ transductants $(53 \%)$ were temperature resistant in the second case, indicating that $l y t-1$ is linked $61 \%$ with the $z f-900:: \operatorname{Tn} 10$ insertion near proU and $53 \%$ with a $s r l:: \operatorname{Tn} 10$ insertion. In accordance with the recommended nomenclature (Chumley et al., 1979), the Tn10 insertion in CCMB1004 has been given the allele number $z f-905:: \operatorname{Tn} 10$. The above results suggest that $l y t-1$, along with the closely linked $z f-905:: \operatorname{Tn} 10$ insertion, lies between the $s r l$ and proU loci on the chromosome.

The $z f-905:: \operatorname{Tn} 10$ insertion was also shown to be $15 \%$ cotransducible with $l y t-2$ in CCMB1002 (data not shown). Since $l y t-1$ and $l y t-2$ are, respectively, $85 \%$ and
$15 \%$ linked with this $\operatorname{Tn} 10$ insertion, it is possible that the two lyt alleles represent different loci. Complementation tests between them have not been done.

\section{Resistance to antibiotic-induced lysis}

It is clear from the data shown in Fig. 1 that the mutants CCMB1001 and CCMB1002 were resistant to lysis by both seminalplasmin $\left(200 \mu \mathrm{g} \mathrm{ml}^{-1}\right)$ and ampicillin $\left(1000 \mu \mathrm{g} \mathrm{ml}^{-1}\right)$ at $37^{\circ} \mathrm{C}$, the temperature at which the mutants could not form colonies, but not at $30^{\circ} \mathrm{C}$, the temperature at which they could grow and form colonies. The results obtained at $42^{\circ} \mathrm{C}$ (data not shown) were essentially similar to those obtained at $37^{\circ} \mathrm{C}$. Resistance to lysis could be seen in terms both of the time taken for the onset of lysis and of the rate of lysis. Mutant CCMB1002 appeared to be the more resistant to lysis, as it lysed only after about $90 \mathrm{~min}$ treatment with ampicillin. At lower concentrations of ampicillin the time taken for the onset of lysis was longer. It is noteworthy that the kinetics of seminalplasmin-induced lysis were very similar to those of ampicillin-induced lysis. The mutants were also similarly resistant to lysis 


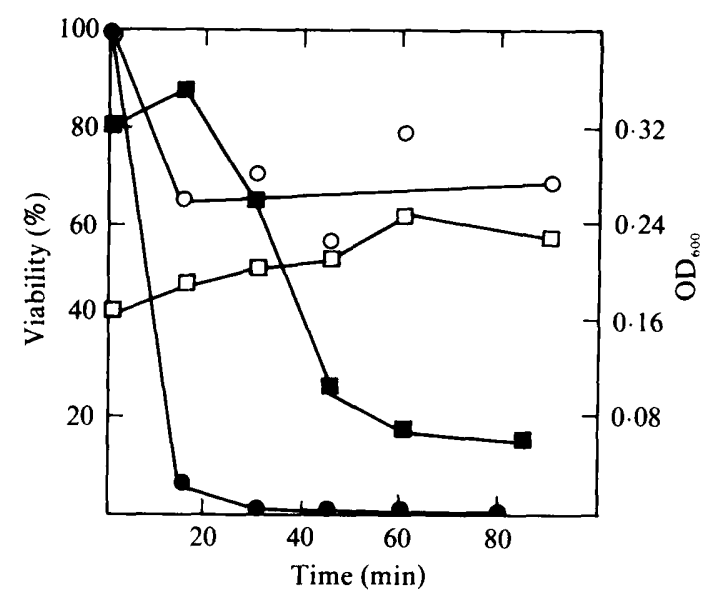

Fig. 2. Effect of ampicillin on viability of mutant CCMB1001 $(l y t-1, \mathrm{ts})$ $(O, \square)$ and its revertant, $\mathrm{CCMB} 1003(O, \square)$. Strains were grown to the exponential phase in TSB at $30^{\circ} \mathrm{C}$, then incubated in a shaking water bath at $37^{\circ} \mathrm{C}$ for $30 \mathrm{~min}$, followed by addition of ampicillin $\left(100 \mu \mathrm{g} \mathrm{ml}^{-1}\right)(t=0)$. At various time intervals, a $1 \mathrm{ml}$ sample was taken, chilled and the $\mathrm{OD}_{600}$ read $(\square, \square)$, while another sample of $0.1 \mathrm{ml}$ was immediately diluted as required, plated on TSB plates and the number of colonies that grew overnight at $30^{\circ} \mathrm{C}$ counted to determine viability $(O, O)$. Initial viability, taken as $100 \%$, was $6 \times 10^{7}$ cells $\mathrm{ml}^{-1}$ in the case of CCMB1001 and $1.6 \times 10^{8}$ cells ml-1 in the case of CCMB 1003. No attempt was made to remove the antibiotic before plating as its concentration after the dilution would be too low to inhibit the growth of colonies on the plate.

Table 2. MTC values of ampicillin and $\mathrm{D}$-cycloserine at $42{ }^{\circ} \mathrm{C}$

The MTC is defined as the highest concentration of antibiotic not inducing lysis within $2 \mathrm{~h}$.

\begin{tabular}{lcc}
\hline & \multicolumn{2}{c}{ MTC value $\left(\mu \mathrm{g} \mathrm{ml}^{-1}\right)$} \\
\cline { 2 - 3 } Strain & Ampicillin & D-Cycloserine \\
\hline C90 & 10 & $<50$ \\
CCMB1001 & 75 & 2000 \\
CCMB1002 & 150 & 4000 \\
\hline \hline
\end{tabular}

induced by two other antibiotics, namely nocardicin and D-cycloserine. Resistance to lysis induced by ampicillin and D-cycloserine could also be seen in terms of the MTC values (Table 2). Here again, CCMB1002 was more resistant than CCMB1001.

As the mutants were resistant to lysis induced by a variety of antibiotics, namely seminalplasmin, ampicillin, D-cycloserine and nocardicin, it was important to see if resistance to lysis induced by all the antibiotics was due to a single mutation. We therefore obtained temperatureresistant revertants of CCMB1001 and CCMB1002 by selecting for colonies that grew at $42{ }^{\circ} \mathrm{C}$; CCMB1003, a revertant of CCMB1001, was studied in detail. The

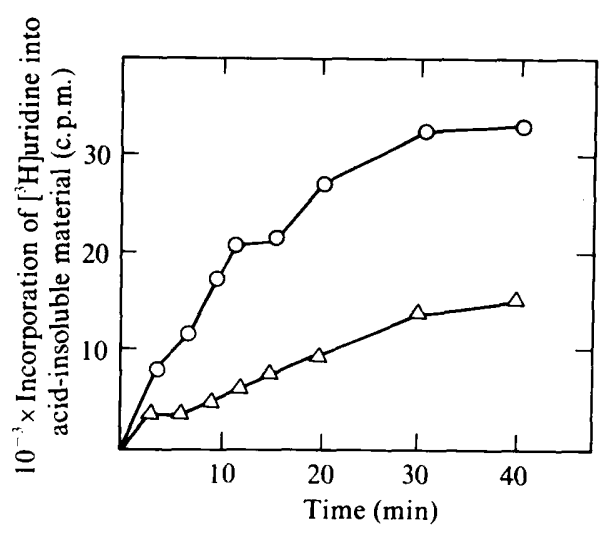

Fig. 3. Effect of seminalplasmin on the synthesis of RNA in mutant CCMB1001 (lyt-1, ts). The strain was grown in TSB at $30^{\circ} \mathrm{C}$ to an $\mathrm{OD}_{600}$ of 0.15 and the culture was preincubated at $37^{\circ} \mathrm{C}$ for $30 \mathrm{~min}$ before studying RNA synthesis at $37^{\circ} \mathrm{C}$ in the presence $(\triangle)$ or absence (O) of seminalplasmin $\left(100 \mu \mathrm{g} \mathrm{ml}^{-1}\right)$, as described in Methods.

revertant was as sensitive as the wild-type to both seminalplasmin- and ampicillin-induced lysis. Essentially similar results were obtained with D-cycloserine and nocardicin. Two other temperature-resistant revertants of CCMB1001 and three revertants of CCMB1002 were also found to be more sensitive to antibiotic-induced lysis than the mutants from which they were derived.

Since the mutants were resistant to lysis induced by ampicillin, we wanted to see if they would also be resistant to the bactericidal activity of ampicillin. The results in Fig. 2 show that mutant CCMB1001 was indeed resistant to the bactericidal activity of ampicillin at $37^{\circ} \mathrm{C}$. These results are in agreement with earlier observations (Shimmin et al., 1984; Kitano \& Tomasz, 1979).

\section{Effect of seminalplasmin on synthesis of RNA by the mutants}

Inhibition of RNA synthesis was shown to be one of the earliest effects of seminalplasmin in $E$. coli (Reddy \& Bhargava, 1978). Our earlier studies (Chitnis et al., 1987) suggested that the inhibitory effect of seminalplasmin upon RNA synthesis occurs independently of its bacteriolytic effect. We therefore studied the effect of seminalplasmin on RNA synthesis by the mutant strain CCMB1001 at $37^{\circ} \mathrm{C}$ (Fig. 3). As one would expect for a temperature-sensitive mutant, the incorporation of $\left[{ }^{3} \mathrm{H}\right]$ uridine into RNA did not increase exponentially with time. Nevertheless, the inhibitory effect of seminalplasmin on RNA synthesis could be seen even at $3 \mathrm{~min}$, the earliest time studied. This observation supports our view that the inhibition of RNA synthesis by seminal- 


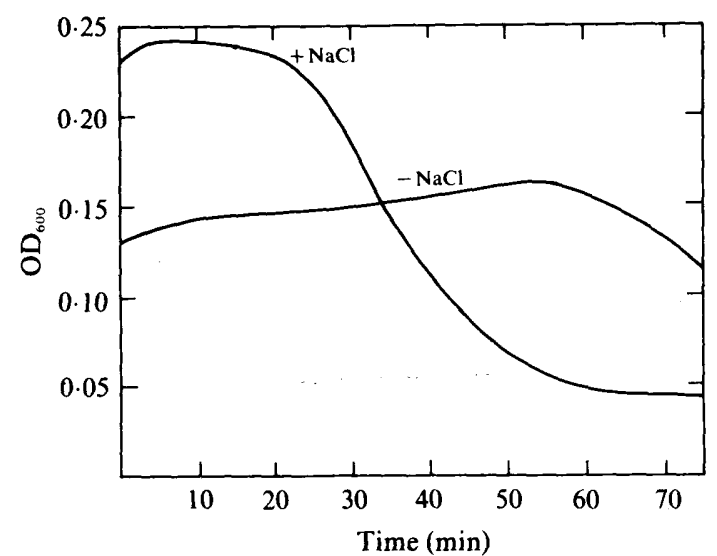

Fig. 4. Effect of $\mathrm{NaCl}$ on ampicillin-induced lysis of mutants CCMB1001 $(l y t-l$, ts). The strain was grown to the exponential phase in TSB at $30^{\circ} \mathrm{C}$ and lysis studied at $37^{\circ} \mathrm{C}$ as in Fig. 1. Na when used, was added to a final concentration of $0.4 \mathrm{M}$ just before adding ampicillin $\left(1000 \mu \mathrm{g} \mathrm{ml}^{-1}\right)$.

plasmin is one of its earliest effects on E. coli and occurs independently of its lytic effect.

\section{Suppression of the lysis-resistant phenotype of the mutants}

Ishiguro and his co-workers had earlier isolated temperature-sensitive mutants of $E$. coli that were resistant to lysis induced by ampicillin and other antibiotics (Harkness \& Ishiguro, 1983; Shimmin et al., 1984). The lysisresistant phenotype of the mutants isolated by Shimmin et al. (1984) was found to be suppressed either by the addition of salts such as $\mathrm{NaCl}$ or by the presence of a relA genotype in the mutant strain (Kusser \& Ishiguro, 1987). We therefore determined whether our mutants behaved similarly. The effect of $\mathrm{NaCl}$ on ampicillin-induced lysis of the mutant CCMB1001 is shown in Fig. $4 . \mathrm{NaCl}$ at a final concentration of $0.4 \mathrm{M}$ suppressed the lysis-resistant phenotype of the mutant. Further, addition of $\mathrm{NaCl}$ to the ampicillin-treated mutant culture resulted in immediate lysis, provided the salt was added at least $20 \mathrm{~min}$ after the addition of ampicillin. Similar results were obtained with the mutant CCMB1002 (data not shown). In the case of either mutant, $\mathrm{NaCl}(0.4 \mathrm{M})$ had no effect on temperature sensitivity for growth. Similar studies could not be done with seminalplasmin-induced lysis because salts inhibit the lytic activity of seminalplasmin (unpublished results).

In order to study the role of the $\mathrm{relA}$ gene in antibioticinduced lysis of the mutants, a P1kc lysate grown on CCMB1005 (lyt-1 zfi-905::Tn10) was used to transduce the isogenic pair of strains NF161 $\left(\mathrm{relA}^{+}\right)$and NF162 (relA) to Tetr. One temperature-sensitive, Tet transductant was chosen in each case and used to study antibioticinduced lysis.

Fig. 5 shows seminalplasmin- and ampicillin-induced lysis of $\mathrm{relA}^{+}$and $\mathrm{relA}$ strains carrying the mutant or wild-type lyt-1 allele at $37^{\circ} \mathrm{C}$. While the lyt-1+ $r e l A^{+}$ (NF-161) and $l y t-1^{+}$relA (NF-162) strains showed little difference in their sensitivity to lysis by seminalplasmin or ampicillin, the lyt-1 relA strain (CCMB1008) was much more sensitive than the lyt-1 relA $A^{+}$strain (CCMB1007). However, the lyt-1 relA strain did not lyse as well as the $l y t-1^{+}$strains NF161 and NF162. Essentially similar results were obtained when the antibiotic-induced lysis was studied at $42^{\circ} \mathrm{C}$ but, as

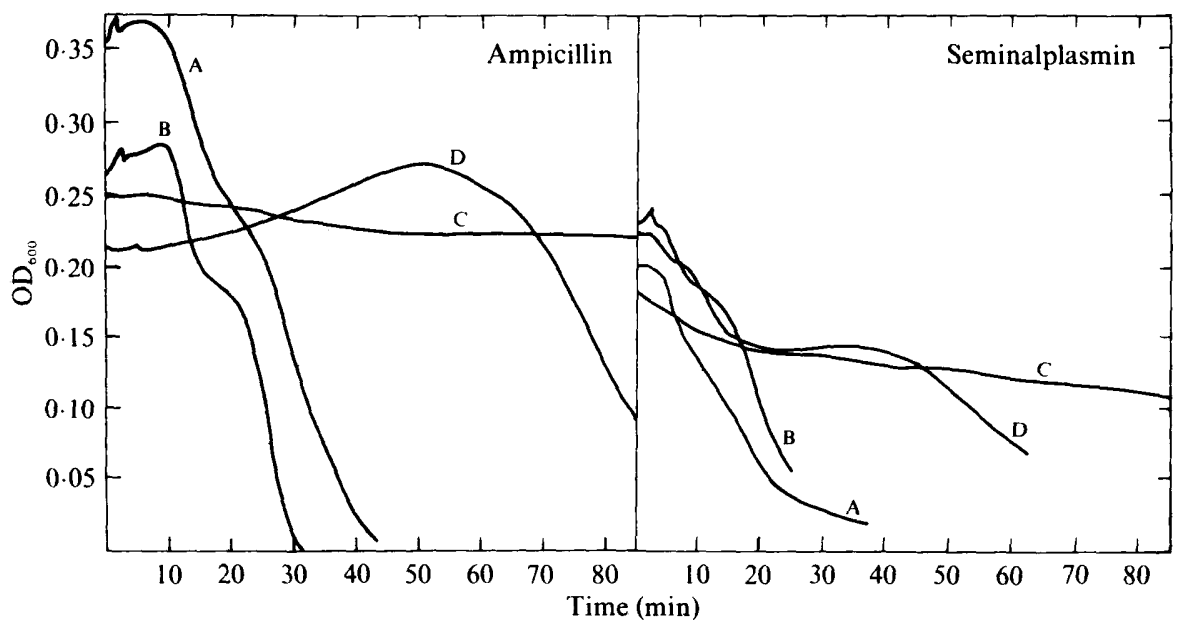

Fig. 5. Suppression of the lysis-resistant phenotype of the $l y t-1$ mutation in relA strains. Strains NF161 $\left(l y t-I^{+}\right.$rel $\left.A^{+}\right)(\mathrm{A}), \mathrm{NF} 162\left(l y t-l^{+}\right.$ $\mathrm{relA})(\mathrm{B}), \mathrm{CCMB} 1007\left(\right.$ lyt-1 relA $\left.{ }^{+}\right)(\mathrm{C})$ and CCMB $1008($ lyt -1 relA $)(\mathrm{D})$ were grown to the exponential phase at $30^{\circ} \mathrm{C}$ in TSB, and lysis induced by ampicillin $\left(1000 \mu \mathrm{g} \mathrm{ml}^{-1}\right)$ or seminalplasmin $\left(200 \mu \mathrm{g} \mathrm{ml}^{-1}\right)$ was studied at $37^{\circ} \mathrm{C}$ as in Fig. 1 . 
expected, there was no difference among the four strains when lysis was studied at $30^{\circ} \mathrm{C}$. These results show that the lysis-resistant phenotype was partially suppressed in strains carrying a $\mathrm{relA}$ genotype and suggest the involvement of factors other than $\mathrm{relA}$ in the lysis resistance of the mutants. Further evidence for the involvement of the relA gene in the lysis resistance of the mutants was obtained by our observation that addition of gentamicin or chloramphenicol, which act as inhibitors of the stringent response, suppressed the lysis resistance of the mutants CCMB1001 and CCMB1002.

\section{Discussion}

\section{Comparison with the mutants isolated earlier}

The mutants isolated by us resembled those of Shimmin et al. (1984) in that (1) they were temperature-sensitive; (2) they were resistant to lysis only at the nonpermissive temperature (Fig. 1); (3) their degree of lysis resistance depended upon the concentration of the antibiotic used; and (4) their lysis-resistant phenotype was suppressed on addition of $\mathrm{NaCl}$ (Fig. 4). The lyt-1 mutation mapped at $58 \mathrm{~min}$, as did lytA, the locus to which one of the two sets of mutations obtained by Shimmin et al. (1984) has been assigned (Kusser \& Ishiguro, 1987).

However, our mutants differed from those of Shimmin et al. (1984) in that they were much more resistant to Dcycloserine-induced lysis (Table 2); also, their lysisresistant phenotype was suppressed only partially in the presence of a mutant relA allele or on addition of inhibitors of the stringent response. Thus, in contrast to the results obtained by Kusser \& Ishiguro (1987), we found that relA strains carrying a mutant $l y t$ allele were much less sensitive to antibiotic-induced lysis than those carrying the wild-type $l y t^{+}$allele (Fig. 5). It remains to be seen whether $l y t-1$ defines a locus different from lyt $A$.

The mutants isolated by Harkness \& Ishiguro (1983) differ from our mutants and from those of Shimmin et al. (1984) in that they are not phenotypically suppressed and are not lysed at all, even at high concentrations of antibiotic.

\section{Evidence suggesting defective autolysis in the mutants}

As the temperature-resistant revertants showed wildtype characteristics with regard to lysis by the various antibiotics, a single mutation must be responsible for the temperature-dependent lysis resistance of the mutants to the various antibiotics. This observation strongly supports the view that the mutants were defective in autolysis.

We discount decreased permeability as an explanation for the observed lysis-resistant phenotype of the mutants
CCMB1001 and CCMB1002, because addition of $\mathrm{NaCl}$ to the mutant cultures treated with ampicillin resulted in immediate lysis provided the salt was added $20 \mathrm{~min}$ after the addition of the antibiotic. The fact that the mutants were sensitive to inhibition of RNA synthesis by seminalplasmin immediately on addition (Fig. 3) also rules out decreased permeability as an explanation for the lysis resistance of these mutants.

Resistance of these temperature-sensitive, autolysisdefective mutants to lysis induced by seminalplasmin at 37 or $42^{\circ} \mathrm{C}$ but not at $30^{\circ} \mathrm{C}$ provides strong evidence for our hypothesis that seminalplasmin, like penicillin, lyses $E$. coli by activating autolysis (Chitnis et al., 1987). However, seminalplasmin-induced lysis differs from that of penicillin in that it does not require continued protein or RNA synthesis (Chitnis et al., 1987). Further, the fact that the mutants were sensitive to inhibition of RNA synthesis by seminalplasmin supports our earlier observation (Chitnis et al., 1987) which indicated that the RNA-synthesis-inhibitory activity of seminalplasmin was independent of its lytic activity.

\section{Mechanism of autolysis deficiency in the mutants}

The mutants described here were resistant to lysis induced by the various antibiotics only at the nonpermissive temperature, the temperature at which they failed to grow. Since non-growing cells autolyse poorly (Leduc et al., 1982), there exists the possibility that the defective autolysis in these mutants is merely due to their defective growth as a result of mutation in an essential gene (not involved in autolysis). This trivial explanation is, we think, unlikely because the mutants were resistant to lysis induced by seminalplasmin, which lyses nongrowing cells such as cells treated with chloramphenicol or rifamycin (Chitnis et al., 1987). We therefore believe that the mutations are in a gene or genes involved in autolysis, and defective autolysis leads to impaired growth.

If these mutants are genuine autolysis-defective mutants, as we think they are, then the defect(s) may lie either in a gene(s) for an autolysin or in a gene(s) involved in regulation of the autolysin activity. We think it unlikely that the mutation(s) is in the gene for an autolysin because the lysis resistance was suppressed in relA strains (Fig. 5). It is most likely, therefore, that the mutants are defective in the regulation of autolysis.

According to Kusser \& Ishiguro (1987), the mutants of Shimmin et al. (1984) were defective in autolysis because they exhibited the stringent response even without starvation for amino acids. This conclusion was based on the following observations: (1) the mutants showed the stringent response at the nonpermissive temperature only, that is, at the temperature at which they were 
resistant to antibiotic-induced lysis; (2) autolysis is known to be inhibited under a stringent response (Kusser \& Ishiguro, 1985); and (3) the lysis-resistant phenotype of the mutants was suppressed in a relA background or on addition of stringent-response inhibitors. Kusser \& Ishiguro (1987) further hypothesized that the loci lyt $A$ and $l y t B$ identified by their mutants interact directly or indirectly with relA to prevent its activation under nonstarvation conditions.

The above model is, however, inadequate to explain the behaviour of our mutants. If the function of the $l y t-1$ product is only to keep the relA product under control (preventing the stringent response under non-starvation conditions), one would expect relA lyt-1 strains to be temperature-resistant. However, the relA lyt-1 strain CCMB1008 was temperature-sensitive, suggesting that the $l y t-1$ product has a role in bacterial growth independent of relA. The relA lyt-1 strain (CCMB1008), although more sensitive to antibiotic-induced lysis than the isogenic relA $A^{+} l y t-1$ strain, was much less sensitive to antibiotic-induced lysis than the relA lyt-1+ $1^{+}$strain, NF162 (Fig. 5). This partial suppression of $l y t-1$ by relA suggests that $l y t-1$ has a role in the regulation of autolysis independent of any role it may have through $\operatorname{rel} A$, and that antibiotic-induced autolysis in $E$. coli may have at least two pathways that differ in their regulation.

We would like to thank J. Gowrishankar for helpful suggestions and B. S. N. Murthy for isolating the seminalplasmin used in this study.

\section{References}

BachmanN, B. J. (1972). Pedigrees of some mutant strains of Escherichia coli K-12. Bacteriological Reviews 36, 525-557.
Chitnis, S. N., Prasad, K. S. N. \& Bhargava, P. M. (1987). Bacteriolytic activity of seminalplasmin. Journal of General Microbiology 133, 1265-1271.

Chumley, F. G., Menzel, R. \& Roth, J. R. (1979). Hfr formation directed by $\mathrm{Tn} 10$. Genetics $91,639-655$.

GOWRISHANKAR, J. (1985). Identification of osmoresponsive genes in Escherichia coli: evidence for participation of potassium and proline transport systems in osmoregulation. Journal of Bacteriology 164, 434-445.

HaRkNess, R. E. \& ISHIGURo, E. E. (1983). Temperature-sensitive autolysis-defective mutants of Escherichia coli. Journal of Bacteriology $155,15-21$.

Kitano, K. \& Tomasz, A. (1979). Escherichia coli mutants tolerant to beta-lactam antibiotics. Journal of Bacteriology 140, 955-963.

KleckNer, N., Barker, D. F., Ross, D. G. \& Botstein, D. (1978). Properties of the translocatable tetracyclin-resistance element Tn10 in Escherichia coli and bacteriophage lambda. Genetics 90, 427-461.

KUSSER, W. \& ISHIGURO, E. E. (1985). Involvement of the relA gene in the autolysis of Escherichia coli induced by inhibitors of peptidoglycan biosynthesis. Journal of Bacteriology 164, 861-865.

KUSSER, W. \& IsHIGURO, E. E. (1987). Suppression of mutations conferring penicillin tolerance by interference with the stringent control mechanism of Escherichia coli. Journal of Bacteriology 169, 4396-4398.

Leduc, M., Kasra, R. \& Van Heijnoort, J. (1982). Induction and control of the autolytic system of Escherichia coli. Journal of Bacteriology 152, 26-34.

Low, K. B. (1972). Escherichia coli K-12, F-prime factors, old and new. Bacteriological Reviews 36, 587-607.

MILLER, J. H. (1972). Experiments in Molecular Genetics, pp. 63-85, 138, 432-433. Cold Spring Harbor, NY: Cold Spring Harbor Laboratory.

Reddy, E. S. P. \& Bhargava, P. M. (1979). Seminalplasmin - an antimicrobial protein from bovine seminal plasma which acts in Escherichia coli by specific inhibition of RNA synthesis. Nature, London 279, 725-728.

Shimmin, L. C., Vanderwel, D., Harkness, R. E., Currie, B. R., Galloway, A. \& Ishiguro, E. E. (1984). Temperature sensitive $\beta$ lactam-tolerant mutants of Escherichia coli. Journal of General Microbiology 130, 1315-1323.

Shivaj, S. \& Bhargava, P. M. (1987). Antifertility factors of mammalian seminal fluid. BioEssays 7, 13-17.

Shivaj, S., Scheit, K. H. \& Bhargava, P. M. (1989). Proteins of Seminal Plasma, pp. 337-349. New York: John Wiley \& Sons. 